\title{
Setting the Children's Teeth on Edge? The Influence of Parental Alcoholism on Children's Wellbeing
}

\author{
JiniPF* and Viju P Devassy ${ }^{\dagger}$
}

The research on the impact of alcoholism on the family indicates that alcoholism often poses threat to the wellbeing of the family, the most affected ones being the other spouse and the children. Alcoholism often poses serious risk to the emotional, cognitive, behavioural, physical and social wellbeing of the abuser, the partner and the children. Most of the researches have explored the impact of parental alcoholism on the negative outcome on psychosocial development of partners and children, very few documented studies have been carried out on the positive aspects of life such as wellbeing and futuristic hope in the children of alcoholic parents (COA). This study attempts to explore the relationship and the difference between QOL and Hope in COA and children of non-alcoholics (CONA). The study was conducted on a sample of 60 children each between the age of 12 to 15 from alcoholics and non-alcoholic parents drawn from a district of Kerala using purposive sampling technique. The measures used were QOL-BREF by WHO (1996) and Children Hope Scale (CHS) by Snyder et al. (1996). The data was first analyzed using the descriptive statistics, the normality of the data was checked using Shapiro Wilk test, Mann-Whitney U test was used to find the difference between the COA and CONA on QOL and Hope. The

* Department of Psychology, Christ University, Bengaluru, India; sr.amalfrancis@gmail.com

† Assistant Professor, Department of Psychology, Christ University, Bengaluru, India; fr.viju@christuniversity.in 
relationship between the variables was assed using Spearman rank correlation. The results of the study indicate that there is significant difference in QOL among the children of alcoholics and non-alcoholics. The COA demonstrated comparatively less Hope than the CONA, however there was no significant difference among them. The QOL and Hope were correlated only among the CONA. The study has implication for positive intervention for the COA, parental and school based interventions such as preventive, remedial and holistic counselling or therapy.

Keywords: Quality of life, Hope, parental alcoholism

Decades of research on the impact of alcoholism on the family indicate that alcoholism often poses threat to the wellbeing of the family, the most affected ones being the other spouse and the children. Quality of life denotes the individual's perceptions of their position in their life, which is based on their socio-cultural milieu and it relates to the value system, goals, concerns, norms and standards, etc. (WHO, 1996). Hope is termed as goal focused thinking where the person uses pathways thinking' and 'agency thinking'. Pathways' thinking involves finding of alternate paths when original ones are impeded (Snyder et al., 1996), and involves positive self-talk and belief about findings alternative paths to goals in mind. Agency thinking also implies the production and use of personal self-statements as motivational or inspirational coping statements in the instances of obstacles and barriers. It has been established that the individuals with high levels of hope experience positive emotions and succeed in the achievement of goals (Carr, 2004). In a human being the growth of hope takes a developmental sequence from infancy through childhood to adolescence (Synder, 2000).

The analysis of the literature has shown the influence of alcoholism in many areas of family and personal life (Johnson, 2001). Alcoholism often poses serious risk to the emotional, cognitive, behavioural, physical and social wellbeing of the abuser, the partner and the children. It leads to the poor mental health (Rognmo, Trovik, Roysamb and Tambs, 2013), and increase the risk for mental distress (Tempier, et al., 2006), mood disorders and anxiety disorders (Dawson, Grant, and Chou, 2007) of the other 
spouse. Further, alcoholic partner shows violence, aggressiveness, anger and helplessness (Parick, 2001). Most of the alcoholic partners have low satisfaction regarding their relationship. Unsatisfying life, verbal, physical, sexual aggression and divorce are some of the end results and major problems in marital life (Dethier, Counerotte and Blacry, 2011). It affects physical and mental health and even leads to family violence. Risk of depressive symptoms increase and there would be decreased marital satisfaction and increase in marital problems among women (Stanley, 2008). The parental alcoholism has an adverse effect on children's holistic development, family functioning, and effective parenting (Johnson and Leff, 1999).

Families with alcoholics have a variety of dysfunction in their family system. The outcome of the studies on the effect of parental alcoholism on children have been varied, some supporting negative impact on the psychosocial development of children (Peleg-Oren and Teichman, 2006) and others showing normal developmental outcomes (Nicholas and Rasmussen, 2006); Schukit, et al., 2008). They also show behavioral and conduct problems than the other children (Haber \& Jacob, 1997). The children of alcoholics have higher risk of alcoholism (Anda, et al., 2002). They are at risk for developing various disorders of childhood and adolescence such as anxiety and depression (Christensen and Bilenberg, 2000), ADHD, conduct problems, Oppositional defiant disorder (Hussong, et al., 2007; Schroeder, Kelley, and Fals-Stewart, 2006). Learning disabilities, anxiety, eating disorder, stress related illness and compulsive achieving are seen in children of alcoholics (Jones, 1995). But the problem of most of the COA remains unclear as show forth socially acceptable and approval seeking coping behavior (Cunradi, Caetano, and Schafer, 2002).

While most of the researches have explored the impact of parental alcoholism on the negative outcome on psychosocial development of partners and children, very few documented studies have been carried out on the positive outcomes such as wellbeing and futuristic hope in the children of alcoholic parents (COA). This study attempts to explore the effect of parental alcoholism on the quality of life and hope among the children of alcoholic parents. It is the part of an extended work that explored the psychosocial 
wellbeing and hope among the spouse and children of alcoholics (COA) and non alcoholics (CONA).

\section{Method}

\section{Objectives}

The present study was undertaken with the following two major objectives.

1. To find the difference in the quality of life and level of hope between the children of alcoholic and non-alcoholic parents

2. To find the relationship between quality of life and hope among the children of alcoholic and non-alcoholic parents

\section{Hypothesis}

1. There is significant difference in the quality of life of children of alcoholics and non-alcoholics.

2. There is significant difference in the level of hope of children of alcoholics and non-alcoholics.

3. There is significant relationship between Quality of Life and Hope among children of alcoholics.

4. There is significant relationship between Quality of Life and Hope among children of non-alcoholics.

\section{Sample}

The sample included 60 children each between the age of 12 to 15 from alcoholics and non-alcoholic parents from Thrissur district of Kerala. Purposive sampling technique was used for this study. Only children of parents who were currently treated for alcoholism were included and the children of parents with any psychiatric disorders were excluded from the study.

\section{Measures}

The biographic information of the respondents was taken using the Socio Demographic Proforma developed by the investigators to gather information on age, gender, socio economic status of the 
parents, and the number of siblings. The informed consent form which outlined the ethical consideration of the research and solicited the voluntary participation of the subject was signed the participants and parents. Confidentiality was assured and freedom to withdraw from the study guaranteed.

\section{Quality of Life Scale (QOL)}

Quality of life scale was constructed by the World Health Organization (WHO) in 1996 was used. The scale consists of four domains: Physical health, Psychological health, Relationship and Environment. Cronbach alpha values for reliability each of the four sub scales scores is 0.85 .

\section{Children Hope Scale (CHS)}

The Hope was constructed by Snyder et al, (1996). They developed six item self-report trait measures applicable for children age 8 to 15. Three items each reflect agency thinking and pathway thinking. Children responded to the items on a 6-point Likert scale continuum. The cronbach alpha score was close to 0.80 .

\section{Ethical Considerations}

The ethical considerations required by APA were meticulously followed. Rapport was maintained and the purpose of the study was explained to the selected sample. The participants signed informed consent forms and prior consent of their parents were taken to carry out the research. As the study was conducted in Kerala, the questionnaires were translated into Malayalam language by an expert. The translated questionnaires are rechecked for validity and reliability.

\section{Statistical Analysis of Data}

The data was first analyzed using the descriptive statistics of mean and standard deviation. The normality of the data was checked using Shapiro Wilk test and the non-parametric test Mann-Whitney $\mathrm{U}$ test was used to find the difference between the children of alcoholics and non-alcoholics on QOL and Hope. The statistical analysis was done using SPSS for windows version 16.0. The 
relationship between the QOL and hope among the COA and CONA was found using Spearman's coefficient of correlation.

\section{Result}

Table 1The differences in the various dimensions of the Quality of life among children of alcoholics and non- alcoholics

\begin{tabular}{|l|l|r|r|r|r|r|r|}
\hline Variable & Category & Mean & SD & $\begin{array}{c}\text { Mean } \\
\text { Rank }\end{array}$ & $\begin{array}{c}\text { Sum of } \\
\text { Ranks }\end{array}$ & $\begin{array}{c}\text { Mann- } \\
\text { Whitney }\end{array}$ & $\begin{array}{c}\text { Signifi } \\
\text { cance }\end{array}$ \\
\hline \multirow{2}{*}{ Phy } & COA & 25.43 & 3.45 & 48.57 & 2914.00 & 1.084 & .000 \\
\cline { 2 - 9 } & CONA & 27.97 & 3.39 & 72.43 & 4346.00 & & \\
\hline \multirow{2}{*}{ Psy } & COA & 20.28 & 4.05 & 52.28 & 3137.00 & 1.307 & .009 \\
\cline { 2 - 9 } & CONA & 22.15 & 3.47 & 68.72 & 4123.00 & & \\
\hline \multirow{2}{*}{ Soc } & COA & 10.65 & 2.53 & 48.37 & 2902.00 & 1.072 & .000 \\
\cline { 2 - 9 } & CONA & 12.33 & 1.63 & 72.63 & 4358.00 & & \\
\hline \multirow{2}{*}{ Enviro } & COA & 27.62 & 4.67 & 47.74 & 2864.50 & 1.034 & .000 \\
\cline { 2 - 9 } & CONA & 31.08 & 4.27 & 73.26 & 4395.50 & & \\
\hline \multirow{2}{*}{$\begin{array}{l}\text { Total } \\
\text { QOL }\end{array}$} & COA & 83.98 & 11.45 & 45.95 & 2757.00 & 927.00 & .000 \\
\cline { 2 - 8 } & CONA & 93.53 & 10.08 & 75.05 & 4503.00 & & \\
\hline
\end{tabular}

$\mathrm{N}=60$

Mann-Whitney $U$ test was used to measure the significant difference between children of alcoholics and non-alcoholics on Quality of Life (QOL). The result suggests that there is a significant difference in the area of physical health $(U=1.084, p=.000<.001)$, psychological health $(U=1.307, p=.009<.01)$, social relationship $(U=1.072, p=.000<.001)$ and in the environmental dimension of QOL $(U=1.034, p=.000<.001)$. In the total score of QOL, the MannWhitney test value $(U=927.000, p=.000<.001)$ is significant at .01 level. Therefore the hypothesis, that there is significant difference in the quality of life of children of alcoholics and non-alcoholics is accepted. 
Table 2The differences in the various dimensions of the Hope among children of alcoholics and non- alcoholics

\begin{tabular}{|l|l|r|r|r|r|r|r|}
\hline Variable & Category & Mean & SD & $\begin{array}{c}\text { Mean } \\
\text { Rank }\end{array}$ & $\begin{array}{c}\text { Sum of } \\
\text { Ranks }\end{array}$ & $\begin{array}{c}\text { Mann- } \\
\text { Whitney }\end{array}$ & $\begin{array}{c}\text { Signific } \\
\text { ance }\end{array}$ \\
\hline \multirow{2}{*}{ Path } & COA & 10.93 & 3.62 & 55.03 & 3302.00 & 1.472 & .084 \\
\cline { 2 - 9 } & CONA & 11.97 & 3.44 & 65.97 & 3958.00 & & \\
\hline \multirow{2}{*}{ Agency } & COA & 11.98 & 3.26 & 60.27 & 3616.00 & 1.786 & .941 \\
\cline { 2 - 8 } & CONA & 12.12 & 3.05 & 60.73 & 3644.00 & & \\
\hline \multirow{2}{*}{$\begin{array}{l}\text { Total } \\
\text { Hope }\end{array}$} & COA & 22.92 & 5.06 & 57.81 & 3468.50 & 1.638 & .395 \\
\cline { 2 - 8 } & CONA & 24.08 & 5.35 & 63.19 & 3791.50 & & \\
\hline
\end{tabular}

Mann- Whitney U-test was used to measure the significant difference between alcoholics' and non-alcoholics' children on Hope. The result of the analysis indicates that there was no significant difference in the area of pathway thinking $(U=1.472, p=$ $.084>.05)$ and in the area of agency thinking $(U=1.786, p=.0 .941>$ .05). Similarly there was no significant difference on the total score of Hope $(U=1.638, p=.395>.05)$. Hence the hypothesis, that there is significant difference in the level of hope of children of alcoholics and non-alcoholics is rejected.

Table 3The correlation between QOL and hope among children of alcoholic parents

\begin{tabular}{|l|r|r|r|r|r|r|r|}
\hline \multicolumn{1}{|c|}{ Variables } & \multicolumn{1}{c|}{1} & \multicolumn{1}{c|}{2} & \multicolumn{1}{c|}{3} & 4 & 5 & 6 & 7 \\
\hline Physical & & & & & & & \\
\hline Psychological & $.370^{* *}$ & & & & & & \\
\hline Social & .196 & $.516^{* *}$ & & & & & \\
\hline Environ & $.356^{* *}$ & $.530^{* *}$ & $.556^{* *}$ & & & & \\
\hline T QOL & $.593^{* *}$ & $.819^{* *}$ & $.704^{* *}$ & $.834^{* *}$ & & & \\
\hline Pathway & $.264^{*}$ & -.030 & .020 & .119 & .079 & & \\
\hline Agency & .054 & -.054 & .023 & -.105 & -.058 & .048 & \\
\hline T hope & .231 & -.060 & -.033 & .000 & -.007 & $.743^{* *}$ & $.659^{* *}$ \\
\hline
\end{tabular}


The result of the correlation analysis shows that though the various internal dimensions of QOL and Hope are mutually correlated significantly, Spearman's rho coefficient correlation showed that there is no significant relationship between total Quality of Life and total Trait Hope $(r=-007, p>.05)$ among COA. So the hypothesis that is significant relationship between quality of life and hope among children of alcoholics is rejected.

Table 4The correlation between QOL and hope among children of non-alcoholic parents

\begin{tabular}{|l|c|c|c|c|c|c|c|}
\hline \multicolumn{1}{|c|}{ Variables } & 1 & 2 & 3 & 4 & 5 & 6 & 7 \\
\hline Physical & & & & & & & \\
\hline Psychological & $.607^{* *}$ & & & & & & \\
\hline Social & $.363^{* *}$ & $.328^{*}$ & & & & & \\
\hline Environ & $.364^{* *}$ & $.516^{* *}$ & $.524^{* *}$ & & & & \\
\hline T QOL & $.767^{* *}$ & $.829^{* *}$ & $.547^{* *}$ & $.791^{* *}$ & & & \\
\hline Pathway & $.296^{*}$ & $.352^{* *}$ & $.262^{*}$ & $.274^{*}$ & $.384^{* *}$ & & \\
\hline Agency & .106 & .244 & -.043 & .246 & .251 & $.361^{* *}$ & \\
\hline T hope & .254 & $.371^{* *}$ & .122 & $.296^{*}$ & $.388^{* *}$ & $.816^{* *}$ & $.806^{* *}$ \\
\hline
\end{tabular}

${ }^{*} \mathrm{p}<.05,{ }^{* *} \mathrm{p}<.01$

The result of the correlation shows that there is significant positive correlation between children of non-alcoholics on QOL and Hope. Spearman's rho coefficient correlation shows that there is significant relationship between total Quality of Life and total Trait Hope $(r=.388, p<.05)$, psychological dimension of QOL and total Trait Hope $(r=.371, p<.05)$ and environmental dimension of QOL and hope $(r=.296, p<.05)$ among children of non-alcoholics. So the hypothesis that there is significant relationship between quality of life and hope among children of non-alcoholics is accepted.

\section{Discussion}

The aim of the study was to examine the differences between the children of alcoholics and non-alcoholics on QOL and Hope. It also assessed the relationship between QOL and hope in COA and CONA. The findings of the present study indicate that significant 
differences exist between children of alcoholics and non-alcoholics on QOL. There is higher level of QOL and Hope among children of non-alcoholics than children of alcoholics, although they did not differ on hope significantly. The adverse effect of alcoholism on the family especially on the other spouse is well established. Tanwar \& Swamy (2009) found that alcohol dependents have significantly adverse effects. It indicated that the level of marital satisfaction, family environmental and quality of life of alcoholics' wives are much lower than non-alcoholics. There could be numerous reasons contributing to this significant difference in QOL in the children. Firstly, their children are not provided proper care even when they fall sick. They also experience a lack of concern and care from their family in their developmental stages such as adolescence. They have not been given due care in their studies and they also experience non-conducive atmosphere for learning. Therefore, children may show poor performance in the school. For such children home becomes a place of anger, hatred and fight. As a result, children do not get opportunities to grow in their skills and talents.

The adolescent COA had manifested lower self-worth and poor adjustment and these deficits could be attributed to increased stress levels and the uncongenial domestic environment the children of alcoholics experience (Stanley \& Vanitha, 2008).

However, there have been studies that did not find the adverse effect of parental alcoholism on children. These studies examined the family dynamics within the alcoholic families. A research on young adults from alcoholic families, in which the family dynamics was less negatively affected by parental alcoholism, showed that they were less likely to report lower quality in dating relationship (Larson, 2004). Another study by Braithwaite (1993) found that there was no direct effect of parental alcoholism on the life satisfaction and adjustment of children of alcoholics, whereas parental alcohol dependency had additive effect on level of life satisfaction. According to Hill (1997) parental alcoholism and childhood socio-economic stress interact. These results indicate that further research be done on various other aspects of the family of origin that promote wellbeing while studying the influence of family history of alcoholism on psychological functioning. 
It was hypothesized that parental alcoholism would lead to lower levels of hope among the COA. It was thought that parental alcoholism would restrain the developmental opportunities for children, and eventually lead them to lose their faith and hopefulness in future, as they do not find any scope for improvement in their life situation. In the present investigation, though it was found that COA has lower levels of hope, the difference was not statistically significant. One major contributing factor could be the influence of teachers, peer group and social support received by the children of non- alcoholics. In addition, they reported to have good hobbies, other leisure time activities and games, which filled them with positive energy and optimism.

The correlation analysis indicated significant association between QOL and Hope among children of non- alcoholics. It was already been found that both QOL and hope are adversely affected in the children of alcoholics. Parental alcoholism may have led to the reduced environmental, social, psychological and physical quality of life, which in turn affect the hope among the children. It would be perhaps due to the lack of support from parents, futuristic vision and ambition, long-term goals, etc. They may not be very optimistic about life. This lack of support could be both emotional and financial. It ultimately results in a state of negative energy. However there was no significant association between the QOL and hope among the COA.

\section{Limitations of the Study}

The present study was limited to only one district of a state in India therefore it cannot be easily generalized to other districts and regions. Though the participants were adequately explained and motivated to answer the measures objectively, the stigma and shame attached to the alcoholism of parents might have led to give socially desirable answers. Factors that make one hopeful were also not explored and studied in detailed.

\section{Implications of the study and Direction for future research}

The study has implications for remedial, preventive and proactive interventions. Therapeutic assistance can be given for severely affected children of alcoholics to develop their quality of life and 
level of hope. Implementation of active interventions to those who are at risk of becoming an alcoholic could be done. Training program may be conducted to raise the awareness about the risks involved in living with alcoholic parents. Holistic counselling for spouses and children of alcoholics should also be integrated.

Future researches must focus on different ways of doing data collection in order to gain more information related to the children of alcoholic and non-alcoholic parents. The demographic variables such as age, education, number of children, socio-economic status, and personality can be taken into consideration because all of these aspects may have an impact on the results. The key factors of Hope among the spouse and children of alcoholics could be studied. On further research, mixed methods or qualitative methods may help to get in depth information with regard to difference and the relationship among the variables.

\section{Conclusion}

The present study was aimed at assessing the relationship between and the difference between QOL and Hope in children of alcoholics and non-alcoholics. The results of the study indicate that there is significant difference in QOL among the children of alcoholics and non-alcoholics. The children of alcoholics showed lower QOL in comparison with the children of non-alcoholics. Children of alcoholics demonstrate comparatively less Hope than the children of non-alcoholics. The QOL and Hope were correlated only among the children of non-alcoholics. The study has implication for positive intervention for the children of alcoholics, parental and school based interventions. Preventive and remedial counselling or therapy may help the children to improve their QOL and level of Hope. Holistic counselling or family counselling for the alcoholic family will also be effective and beneficial.

\section{References}

Anda, R. F., Whitfield, C. L., Felitti, V. J., Chapman, D., Edwards, V. J., Dube, S. R., Williamson, D. F. (2002). Adverse childhood experiences, alcoholic parents, and later risk of alcoholism and depression. Psychiatric Services, 53, 1001-1009. 
Braithwaite, V. (1993). Life satisfaction and adjustment of children of alcoholics: The effects of parental drinking, family disorganization and survival roles. British Journal of Clinical Psychology, 32, 417- 429.

Carr, A. (2004). Positive Psychology. New York: Routledge.

Christensen, H. B., Bilenberg, N. (2000). Behavioural and emotional problems in children of alcoholic mothers and fathers. European Child and Adolescent Psychiatry, 9, 219-226.

Cunradi, C, Caetano, R., \& Schafer, J. (2002). Alcohol-related problems, drug use, and male intimate partner violence severity among US couples. Alcoholism: Clinical and Experimental Research, 26 (4), 493-500.

Dawson, D. A., Grant, B. F., Chou, S. P. (2007). The impact of partner alcohol problems on women's physical and mental health. Journal of Studies on Alcohol Drugs, 68, 66-75.

Dethier,M., Counerotte. C \& Blairy.S (2011). Marital satisfaction in couples with an alcoholic husband. Journal of Family Violence, 26, 151-162.

Haber, J. R., \& Jacob, T. (1997). Marital interactions of male versus female alcoholics. Family Process, 36, 385-402.

Hill, E. (1997). Adulthood functioning: the joint effects of parental alcoholism, gender and childhood socio-economic stress- Alcoholic Addiction, 92(5), 585-596.

Hussong, A.M., Wirth, R. J., Edwards, M.C., Curran, P.J., Chassin, L.A., Zucker, R.A. (2007). Externalizing symptoms among children of alcoholic parents: entry points for an antisocial pathway to alcoholism. Journal of Abnormal Psychology, 116, 529-542.

Johnson, H. (2001). Contrasting views of the role of alcohol in cases of wife assault. Journal of Interpersonal Violence, 16(1), 54-72.

Johnson, J.L. \& Leff, M. (1999). Children of substance abusers: Overview of research findings. Pediatrics, 103 (2), 1085-1099.

Jones, J. C. (1995). Adult children of alcoholics: Characteristics of students in a university setting. Journal of Alcohol \& Drug Education, 40(2), 58-69

Larson, J. M. (2004). Family process as a mediator of the negative effects of parental alcoholism on young adult dating relationships. American Journal of Family Therapy, 32(4), 289-304.

Nicholas, K.B., Rasmussen, E.H. (2006). Childhood abusive and supportive experiences, inter-parental violence, and parental alcohol use: prediction and young adult depressive symptoms and aggression. Journal of Family Violence, 21, 43-61.

Parick, J. (2001). Dimensions of functioning in alcoholic and nonalcoholic families. Journal of Mental Health Counseling, 23(2), 127 
Peleg-Oren, N., Teichman, M. (2006). Young children of parents with substance use disorders (SUD): a review of the literature and implications for social work practice, Journal of Social Work Practice in Addictions, 6, 49-61.

Rognmo, K., Torvik, F.A., Røysamb, E., \&Tambs, K. (2013). Alcohol use and spousal mental distress in a population sample: the nordtrøndelag health study. BMC Public Health, 13, 1-13.

Schroeder, V., Kelley, M.L., Fals-Stewart, W. (2006). Effects of parental substance abuse on youth in their homes. Prevention Researcher, 13, 1013.

Schuckit, M.A., Smith, T.L., Pierson, J., Trim, R., Danko, G.P. (2008). Externalizing disorders in the offspring from the San Diego prospective study of alcoholism. Journal of Psychiatric Research, 42, 644652.

Snyder, C.R. (2000). Hypothesis: There is Hope. In C.R. Snyder (Eds.), Hand book of Hope Theory, Measures and Applications (pp.3-21). San Diego: Academic Press.

Stanley, S. (2008). Interpersonal violence in alcohol complicated marital relationships. Journal of Family Violence, 23(8), 767-776.

Stanley, S. \&Vanitha, C. (2008). Psychosocial correlates in adolescent children of alcoholics- implications for intervention. International Journal of Psychosocial Rehabilitation, 12 (2), 67 -80.

Synder, et al. (1996). Development and validation of the state trait hope scale. Journal of Personality and Social Psychology, 70, 321-335.

Tanwar\&Swamy. (2009). Alcohol dependence and its influences on marital satisfaction, family environment and quality of life of the spouses. http://www.iacp.in/2009/06/alcohol-dependence-and-itsinfluences.html, retrieved July.

Tempier, R., Boyer, R., Lambert, J., Mosier, K., Duncan, C. R. (2006). Psychological distress among female spouses of male at risk drinkers. Alcohol, 40, 41-49. 